\section{The Effect of Climate and the Equator on the Total Coronavirus Cases of the Nine Countries from Africa}

\author{
Hanane Bougherara ${ }^{1}$, Said Benramache ${ }^{1^{*}}$
}

${ }^{1}$ Biskra University, 07000, Biskra, Algeria

\section{Correspondence:}

Said Benramache

Address: Biskra University, 07000, Biskra, Algeria

Email: benramache.said@gmail.com

Received: 27.04.2020,

Accepted: 06.05 .2020

https://doi.org/10.5799/jcei/8263

\begin{abstract}
On the 01 March, 2020, an outbreak of coronavirus disease 2019 (COVID-19) has resulted in 88585 confirmed cases. African countries move from COVID-19 readiness to respond as many confirmed cases. The equator differs from the rest of the world in its climate and environment. In this work we conducted a comparative study of cases of coronavirus infection and the number of deaths, this study was investigated in nine countries from Africa with the same climate and which belong to the equator, where the results were compared with the relation to the general population and total area. From the studied results, we found a zero \% of the Deaths for Rwanda, Equatorial Guinea and Uganda. The equator countries of Africa have not been affected much by this virus, Climate found in the equator countries helped these countries to obtain a small number of injuries, Air and temperature affected the number of deaths, and the equator countries authorize its climate to help them acquire special immunity.

Keywords: COVID-19, Africa, climate, Equator
\end{abstract}

\section{INTRODUCTION}

A novel coronavirus has resulted in an ongoing outbreak of viral pneumonia in China [1-3]. Person-to-person the transmission has been demonstrated, but, to our knowledge, transmission of the novel coronavirus that causes coronavirus disease 2019 (COVID-19) from an asymptomatic carrier with normal chest computed tomography (CT) findings has not been reported [1-4]. The coronavirus COVID-19 is affecting 209 countries and territories around the world and 2 international conveyances [5]. However, there are many challenges to such analyzes, especially in real time [6]. There may be a delay in the onset of symptoms resulting from the incubation period and a delay in confirming the cases resulting from the ability to detect and test [7].

The National Institute for Biomedical Research, based in Kinshasa, coordinates testing and processes all samples across the country of 80 million people. The government should decentralize its testing capacities to identify people infected with COVID-19 more effectively, and isolate and start treating positive cases faster, Human Rights Watch said [8].

Behavior change calls for a paradigm shift and understanding of the lock-in requires dynamics of sustaining people and better knowledge of how the country will be governed. Nevertheless, the outcome of the current COVID-19 currently in Kenya depends on governance systems in an increasingly neoliberal world that closes off avenues for envisioning possible worst cases scenarios [9].

Tanzanian health authorities said 53 new confirmed cases of COVID-19 were recorded on Thursday and Friday bringing the total number of cases in the East African country to 147. Ummy Mwalimu, the Minister of Health, Community Development, Gender, Elderly and Children, said in a statement that all the new cases were Tanzanians [10].

Rwanda has on Saturday, April 18 confirmed one new COVID-19 cases bringing the total to 144 cases, while four COVID-19 patients recovered. This brought the number of recovered patients to 69 while the number of active cases now stands at 75 
[11].

Somalia has confirmed 19 new COVID-19 cases, taking the country's total tally to 135 . The Horn of African country's health ministry announced the new figures on Saturday, noting that two more patients had died of the disease. Seven people have so far succumbed to COVID-19 in the country. Somalia is one of 52 African countries that have recorded cases of COVID-19. The continent's confirmed COVID-19 cases have surpassed 20,000, with over 1,000 deaths. Over 4,600 patients have successfully recovered [12].

Gabon recorded 13 new cases of COVID-19 contamination on April 17, announced the spokesman of the COVID-19 Committee, Doctor Guy Patrick Obiang Ndong. Doctor Guy Patrick Obiang Ndong also announced good news: Gabon has registered a new cure which brings to 7 the total number of people healed in Gabon from this dreaded disease. To date, the total toll of COVID-19 in Gabon is 108 positive cases including 7 cures and 1 death [13].

While in Malabo, Equatorial Guinea, there is about 18,725 typical coronaviruses (common cold) reports every year and about 16 people die from it, you might be wondering how many people have been infected by the new COVID-19 deadly coronavirus originating from China. While in Equatorial Guinea there are 79 officially confirmed cases of the deadly virus, let's see if we have any confirmed cases in Malabo [14].

In the Uganda, 1,162 samples tested negative for COVID19,839 samples were from truck drivers at border points of entry, 323 samples were from individuals under institutional quarantine and contacts, 8 new recoveries today; total:20 recoveries, COVID-19 confirmed Cases stand at 55 in Uganda, Distributed by APO Group on behalf of Ministry of Health - Republic of Uganda [15].

As of 10 April, 5 cases of COVID-19 have been confirmed in Burundi. On 12 April, Burundi recorded its first death related to COVID-19. A total of 34 people identified as contacts and monitored by the technical teams of the Ministry of Public Health and the Fight against AIDS (MSPLS): All these people were tested with negative results [16].

The recent pandemic caused by the novel human coronavirus, referrred to as severe acute respiratory syndrome coronavirus 2 (SARS-CoV-2), not only is having a great impact on the health care systems and economies in all continents but it is also causing radical changes of common habits and life styles [17-23]. In the present work, we conducted a comparative study of cases of coronavirus infection and the number of deaths, this study was investigated in nine countries from Africa with the same climate and which belong to the equator, where the results were compared with the relation to the general population and total area.

\section{RESEARCH METHOD}

Through our observation about the spread of coronavirus (COVID-19) that it spreads from one country to another at different speeds, the enemy may decrease its speed through several reasons, including heat, humidity, population, area, and industries that pollute the atmosphere, in addition to a factor the fear. All of these reasons make the speed of the enemy differ from one region to another. Our study focused on the climate and factors in the region of the African countries where the Equator is located.

The equator differs from the rest of the world in its climate and environment, in addition to its geographical characteristics, the tropical climate remains about one year round, and the prevailing patterns are warm and humid or warm and dry, and most tropical regions are also characterized as wet. These climatic patterns occur because the region at the equator receives a lot of incoming sunlight, and when one moves away from the tropics, the levels of solar radiation change, allowing other climates to appear, so moderate weather occurs in the mid-latitudes and the cold weather at the poles [24].

According to the Guardian, research indicates that people who live in countries far from the equator develop symptoms of multiple sclerosis at a young age, and it is believed that both the genetic and environmental factors are behind the development of MS, researchers suggest that this association may be caused by differences in levels of Sunlight, and therefore vitamin $\mathrm{D}$ levels, are produced in the skin by ultraviolet radiation [24,25].

\section{RESULT}

Table 1 shows the variation of the total cases, total deaths, total tests, general population and total area of the Africa countries DRC, Kenya, Tanzania, Rwanda, Somalia, Gabon, Equatorial Guinea, Uganda and Burundi.

Figure 1 shows the variation of the Total Coronavirus Cases of the nine countries from Africa, which is observed from 1 March 2020 to 19 April 2020.

Figure 2 shows the variation of the Total Deaths Cases of the nine countries from Africa, which is observed from 1 March 2020 to 19 April 2020.

Figure 3 shows the variation of the Cases rate with Population and Area of the nine countries in Africa from 1 March 2020 to 19 April 2020.

Figure 4 shows the variation of the Deaths rate with Population and Area of the nine countries in the Africa from 1 March 2020 to 19 April 2020.

\section{DISCUSSION}

Based on the result, it can observe that the Total Coronavirus Cases in the DRC, Kenya are the highest values (see Figure 1). However, Equatorial Guinea, Uganda and Burundi have the minimum cases due to the good climate and respect for state education in domestic stone. 
The Effect of Climate and the Equator on the Total Coronavirus Cases of the Nine Countries from Africa

Table 1. The variation of the total cases, total deaths, total tests, general population and total area of DRC, Kenya, Tanzania, Rwanda, Somalia, Gabon, Equatorial Guinea, Uganda and Burundi

\begin{tabular}{cccccc}
\hline Countries & Total cases & Deaths & Total tests & General population & Total area \\
\hline DRC & 307 & 25 & - & 84.07 millions (2018) & $2,345 \mathrm{millions} \mathrm{km}^{2}$ \\
\hline Kenya & 262 & 12 & 10784 & 49.7 millions (2014) & $580367 \mathrm{~km} 2$ \\
\hline Tanzania & 147 & 5 & - & 56,3 millions (2018) & $947,303 \mathrm{~km} 2$ \\
\hline Rwanda & 144 & 0 & 6237 & 12,3 millions (2018) & $26338 \mathrm{~km} 2$ \\
\hline Somalia & 135 & 7 & - & 15,01 millions (2018) & $637,657 \mathrm{~km} 2$ \\
\hline Gabon & 108 & 1 & 572 & 2,119 millions (2018) & $267667 \mathrm{~km} 2$ \\
\hline Equatorial Guinea & 79 & 0 & 854 & 1,309 million (2018) & $28,050 \mathrm{~km} 2$ \\
\hline Uganda & 55 & 0 & 9975 & 42,7 million (2018) & $241,038 \mathrm{~km} 2$ \\
\hline Burundi & 5 & 1 & 80 & 11.9 million (2018) & $27834 \mathrm{~km} 2$
\end{tabular}

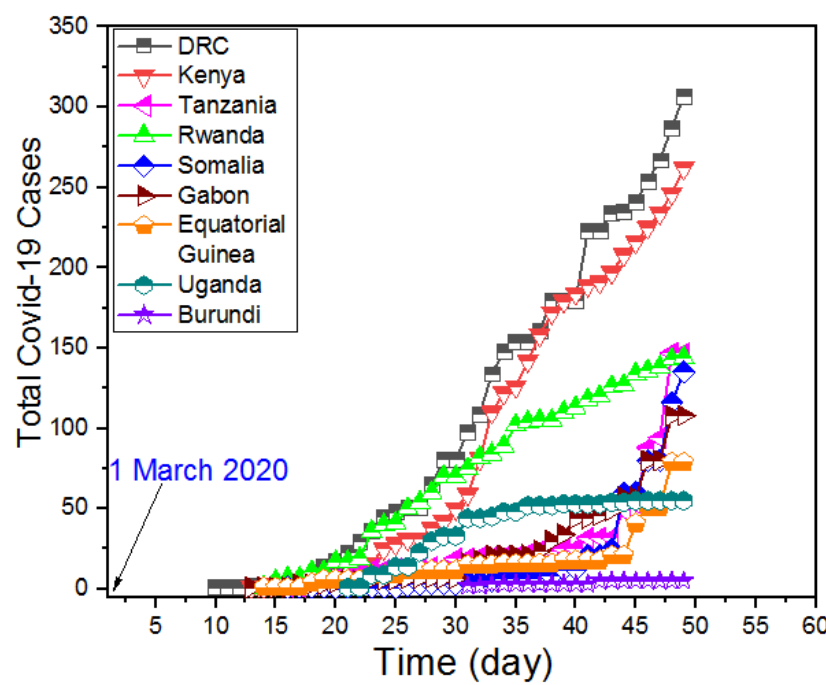

Figure 1. The variation of the Total Coronavirus Cases of the nine countries in Africa from 1 March 2020 to 19 April 2020

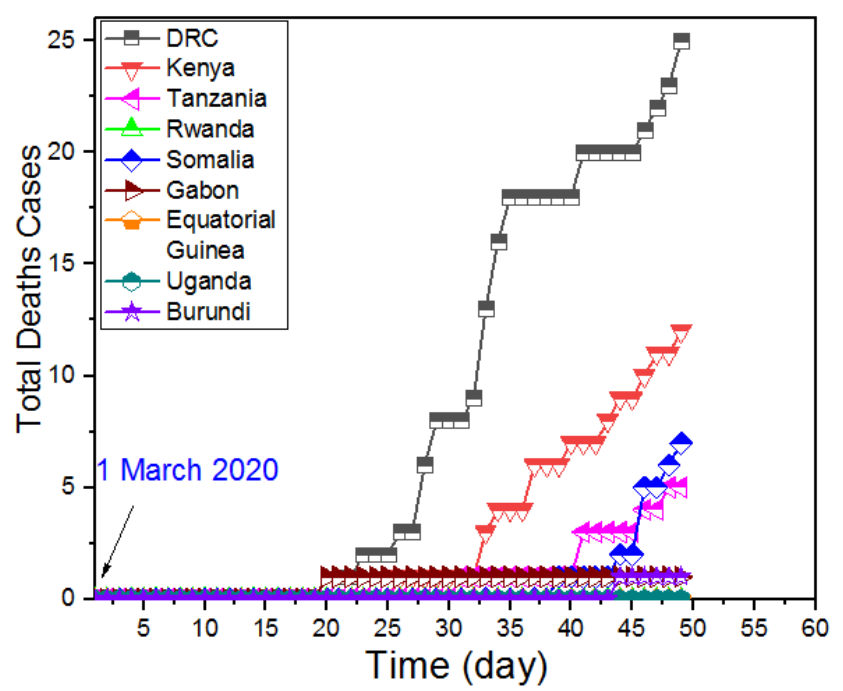

Figure 2. The variation of the Total Deaths Cases of the nine countries in Africa from 1 March 2020 to 19 April 2020

There are observe three countries registered and no deaths (see Figure 2), it are Equatorial Guinea, Uganda and

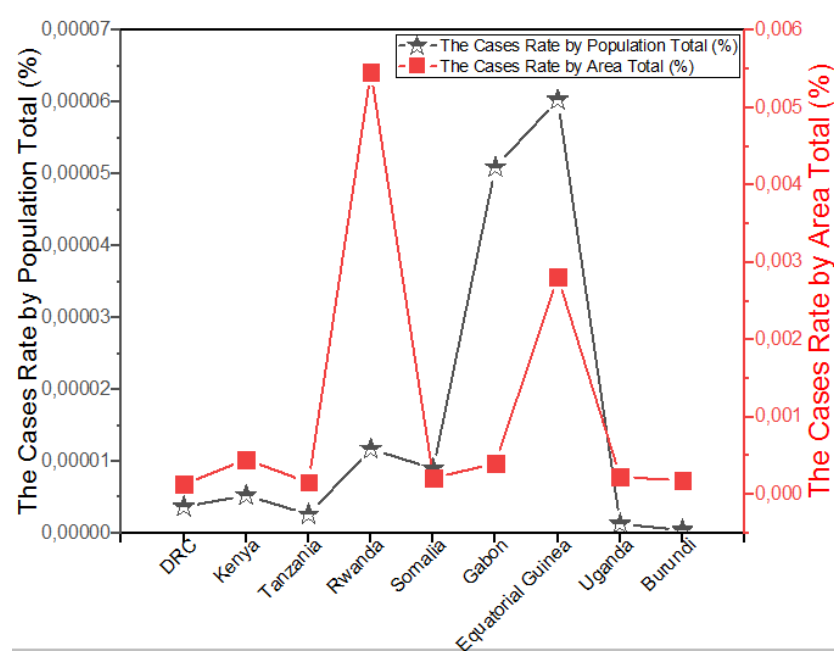

Figure 3. The variation of the Cases rate with Population and Area of the nine countries in Africa from 1 March 2020 to 19 April 2020

Rwanda due to due to the fresh air, the good climate and respect for state education in domestic stone.

We have observed that the highest Cases rates by Population were found for Gabon and Uganda (see Figure 3). However, Rwanda and Equatorial Guinea have the highest Cases rates by Area. As for the other countries have very small rates due to the fresh air, the good climate and respect for state education in domestic stone.

We have obtained that the lowest Deaths rates were found to be zero \% for Rwanda, Equatorial Guinea and Uganda due to the fresh air, the good climate and respect for state education in domestic stone (see Figure 4).

\section{CONCLUSIONS}

In conclusion, the coronavirus COVID-19 is affecting 209 countries and territories around the world and as of 01 March, 2020, an outbreak of coronavirus disease 2019 (COVID-19) has resulted in 88585 confirmed cases. African countries move from COVID-19 readiness to respond as many confirmed cases. The equator differs from the rest of the world in its climate and environment. In this work we 


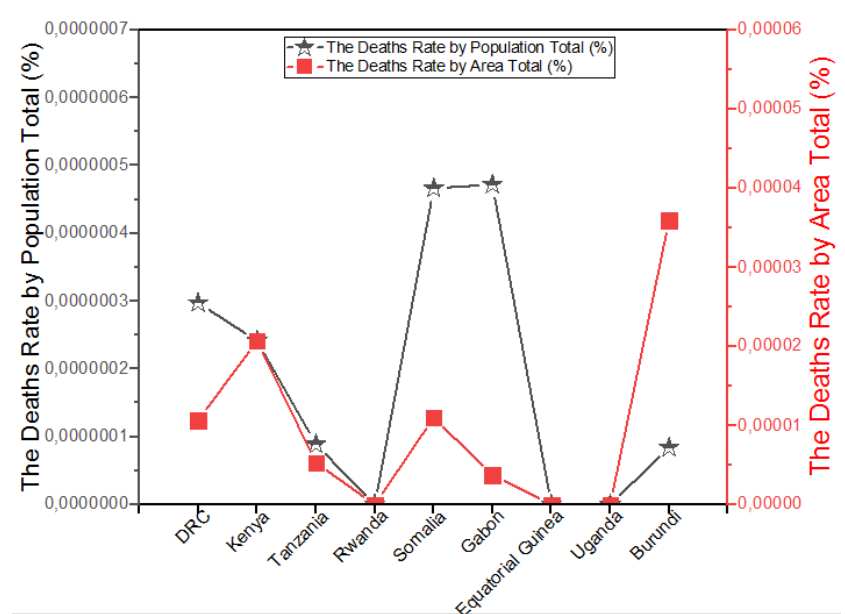

Figure 4. The variation of the Deaths rate with Population and Area of the nine countries in Africa from 1 March 2020 to 19 April 2020

conducted a comparative study of cases of coronavirus infection and the number of deaths, this study was investigated in nine countries from Africa with the same climate and which belong to the equator, where the results were compared with the relation to the general population and total area. Through the studied results, the following results were obtained.

$\checkmark$ We found a zero \% of the Deaths for Rwanda, Equatorial Guinea and Uganda.

$\checkmark$ The equator countries of Africa have not been affected much by this virus.

$\checkmark$ Climate found in the equator countries helped these countries to obtain a small number of injuries.

$\checkmark$ Air and temperature affected the number of deaths.

$\checkmark$ The equator countries authorize its climate to help them acquire special immunity.

Declaration of interest: The authors report no conflicts of interest. Financial Disclosure: No financial support was received.

\section{REFERENCES}

1. Bai Y, Yao L, Wei T, Tian F, et al. MD. American Medical Association. Available at: https://jamanetwork. com/ (Accessed: 8 April 2020).

2. Dakhil ZA, Farhan HA. Cardiovascular Impacts of COVID-19 Pandemic: From Presentation to Management: Current and Future Perspectives. J Clin Exp Invest. 2020;11(3):em00739. doi: 10.5799/jcei/7941.

3. Shereen MA, et al. COVID-19 infection: origin, transmission, and characteristics of human coronaviruses. Journal of Advanced Research, 2020. doi: 10.1016/j.jare.2020.03.005.

4. Cakir Z, Savas HB. A Mathematical Modelling Approach in the Spread of the Novel 2019 Coronavirus SARS-CoV-2 (COVID-19) Pandemic. Electron J Gen Med. 2020; 17(4): em205. doi: 10.29333/ejgm/7861.
5. COVID-19 research. Available at: https://www.worldo meters.info/coronavirus/\#countries (Accessed: 19 April 2020).

6. Aljofan M, Gaipov A. COVID-19 Treatment: The Race Against Time. Electron J Gen Med. 2020; 17(6): em227. doi: $10.29333 /$ ejgm/7890.

7. Gondauri D, Mikautadze E, Batiashvili M. Research on COVID-19 Virus Spreading Statistics based on the Examples of the Cases from Different Countries. Electron J Gen Med. 2020; 17(4): em209. doi: 10.29333/ejgm/7869.

8. DR Congo: Respecting Rights Key Amid COVID-19. 2020. Available at: https://www.hrw.org/news/2020/04/ 03/dr-congo-respecting-rights-key-amid-covid-19

9. Mbae N. COVID-19 in Kenya. Electron J Gen Med. 2020; 17(6): em231. doi: 10.29333/ejgm/7896.

10. COVID-19 research in Tanzania. 2020. Available at: https://africa.cgtn.com/2020/04/17/tanzanias-numberof-covid-19-cases-rises-sharply-to-147/ (Accessed: 19 April 2020).

11. COVID-19 research in Rwanda. 2020. Available at: https://www.pmldaily.com/news/2020/04/pml-dailycoronavirus-update-rwanda-covid-19-cases-rise-to144-somalia-records-18-infections-on-saturday-asegypt-and-algeria-curves-reach-worrying-levels.html (Accessed: 19 April 2020).

12. COVID-19 research in Somalia. 2020. Available at: https://newsaf.cgtn.com/news/2020-04-19/Somalia-sCOVID-19-tally-hits-135-PNFhx7NKEg/index.html (Accessed: 19 April 2020).

13. COVID-19 research in Gabon. 2020. Available at: https://www.gabonactu.com/covid-19-13-nouveauxcas-positifs-au-gabon-ce-17-avril-108-au-total/ (Accessed: 19 April 2020).

14. COVID-19 research in Equatorial Guinea. 2020. Available at: https://www.ovulation-calculators.com/ coronavirus/gq/malabo/ (Accessed: 19 April 2020).

15. COVID-19 research in Uganda. 2020. Available at: https://www.cnbcafrica.com/africa-press-office/2020/ 04/17/coronavirus-uganda-covid-19-confirmed-casesstand-at-55-in-uganda/ (Accessed: 19 April 2020)

16. COVID-19 research in Burundi. 2020. Available at: https://reliefweb.int/report/burundi/burundi-covid-19flash-update-no-1-08-april-2020 (Accessed: 19 April 2020).

17. DECARO, Nicola; LORUSSO, Alessio. Novel human coronavirus (SARS-CoV-2): a lesson from animal coronaviruses. Veterinary Microbiology, 2020:108693. doi: 10.1016/j.vetmic.2020.108693.

18. Hachim SK. The Convalescent Serum for Treatment of COVID-19 Infection: Review. European Journal of Medical and Educational Technologies. 2020; 13(1): em2005. doi: 10.30935/ejmets/8016. 
19. Killerby ME, et al. Middle East respiratory syndrome coronavirus transmission. Emerging infectious diseases, 2020; 26(2): 191-8. doi: 10.3201/eid2602.190697.

20. $\mathrm{Li} \mathrm{H}$, et al. Human-animal interactions and bat coronavirus spillover potential among rural residents in Southern China. Biosafety and Health, 2019; 1(2): 84-90. doi: 10.1016/j.bsheal.2019.10.004.

21. Riou J, Althaus CL. Pattern of early human-to-human transmission of Wuhan 2019 novel coronavirus (2019nCoV), December 2019 to January 2020. Eurosurveillance, 2020; 25(4): 2000058. doi: 10.2807/1560-7917.ES.2020.25.4.2000058.

22. Shereen MA, et al. COVID-19 infection: origin, transmission, and characteristics of human coronaviruses. Journal of Advanced Research, 2020. doi: 10.1016/j.jare.2020.03.005.
23. $\mathrm{Xu} \mathrm{J}$, et al. Systematic comparison of two animal-tohuman transmitted human coronaviruses: SARS-CoV-2 and SARS-CoV. Viruses, 2020; 12(2): 244. doi: $10.3390 / \mathrm{v} 12020244$.

24. Effect of climate in the equator countries on medical. Available at: https://arabicpost.net/\%D8\%B9\%D9\%84\% D9\%88\%D9\%85/\%D8\%B7\%D8\%A8/2019/10/26/\%D8 \%AA\%D8\%A3\%D8\%AB\%D9\%8A\%D8\%B1-\%D8\%A7 \%D9\%84\%D9\%82\%D8\%B1\%D8\%A8-\%D9\%85\%D9\% 86-\%D8\%AE\%D8\%B7-\%D8\%A7\%D9\%84\%D8\%A7\% D8\%B3\%D8\%AA\%D9\%88\%D8\%A7\%D8\%A1-\%D8\% B9\%D9\%84\%D9\%89-\%D8\%A7\%D9\%84\%D8\%AA\% D9\%81\%D9\%83\%D9\%8A\%D8\%B1/ (Accessed: 19 April 2020).

25. Effect of climate in the equator countries on medical. 2020. Available at: https://www.theguardian.com/soc iety/2016/nov/03/age-of-onset-for-multiple-sclerosislinked-to-distance-from-equator (Accessed: 19 April 2020). 